\title{
Manipulating the Performance and Oxidative Responses of Dairy Cattle Under Long-term Environmental Heat Stress Upon Zinc-Methionine Complex Dietary Inclusion
}

Mohsen Danesh Mesgaran ( $\nabla$ danesh@um.ac.ir)

Ferdowsi University of Mashhad

Hassan Kargar

Ferdowsi University of Mashhad

Rieke Janssen

Ferdowsi University of Mashhad

Sadjad Danesh Mesgaran

Ferdowsi University of Mashhad

Aghil Ghesmati

Ferdowsi University of Mashhad

Amirmansour Vatankhah

Tabriz University of Medical Sciences

\section{Research Article}

Keywords: Cattle, Heat stress, Zinc-Methionine, Milk, Oxidative stress, Health

Posted Date: February 3rd, 2022

DOI: https://doi.org/10.21203/rs.3.rs-1306298/v1

License: (c) (i) This work is licensed under a Creative Commons Attribution 4.0 International License.

Read Full License 


\section{Abstract}

Dairy cows are susceptible to heat stress due to levels of milk production and feed intake. Dietary supplemental amino acids, particularly rate-limiting amino acids e.g., methionine (Met), may alleviate the potential negative consequences. Zinc $(\mathrm{Zn})$ is beneficial to the immune system and mammary gland development during heat stress. We investigated the impact of a source of rumen-protected Zn-Met complex (Loprotin, Kaesler Nutrition $\mathrm{GmbH}$, Cuxhaven, Germany) in high producing Holstein cows during a long-term environmental heat stress period. Sixty-two multiparous Holstein lactating cows were allocated in a completely randomized design to 1 of 2 dietary treatments as basal diet without (control) or with supplemental Zn-Met complex (RPZM) at $0.131 \%$ of diet DM. Cows in the RPZM group had higher energy-corrected milk as well as milk fat and protein concentration. Zn-Met complex supplemented cows had lower haptoglobin and IL-1B concentration compared with the control. RPZM supplementation resulted in better oxidative status, indicated by higher total antioxidant status and lower malondialdehyde concentrations. Enhanced performance of animals upon Zn-Met complex supplementation could be partly the result of improved oxidative and immune status. Data generated herein could develop novel feeding concepts, i.e., particular feed additives, which can be practically implemented to maintain animal's productivity and longevity during periods of heat stress.

\section{Introduction}

Dairy cows are susceptible to thermal stress due to their level of milk production and feed intake. High genetic merit modern dairy cows undergo thermal stress starting at an average temperature-humidity index (THI) of 68, whereas at THI> 72 significant losses in milk production has been observed[1]. During environmental heat stress, the amount of energy expended by the cow will increase. The additional energy requirement of the animal must be covered by increasing the dry matter intake (DMI). However, under heat stress DMI typically decreases i.e., cows will be subjected to unfavorable energy status. Consequently, the milk production (both volume and components) and reproductive indices would be impaired[1]. Decline in the daily DMI causes lower uptake of nutrients by the animals, particularly amino acids (AA). Feeding AA deficient diets has been resulted in heat production elevation in the animals, due to the increase of tissue protein turnover[2]. Optimizing post-ruminal levels of rate-limiting AA such as methionine (Met), i.e., metabolisable Met concentration, might alleviate the negative consequences of heat stress[2]. Including sufficient amount of AA in dairy cattle diets has been an important purpose of dairies nutritional management.Dietary AA may enhance health and lactation performance including milk protein and fat yield [3]. Methionine is an essential AA for growth and tissue repair, in which improves the metabolism and health of dairy cows[4].Methionine as a "functional AA" has also an important physiologic actions beyond protein synthesis, such as DNA methylation, regulation of translation, synthesis of other molecules (e.g., choline and polyamines), altering the immune system as well as oxidative metabolism[4, 5].Recent studies indicated that feeding rumen-protected Metcould increase milk protein yield[6]. Enhanced milk protein synthesis may be related to the link between Met and branched- 
chain AA regarding the regulation of biosynthesis of milk protein[7]. Methionine also promotes the absorption of zinc ( $\mathrm{Zn})[8]$ and acts as a lipotropic agent to prevent excess fat build-up in the liver [9].

Zinc, one of the most essential trace mineral for animals, is incorporated into a variety of proteins and enzymes that are involved in a wide range of physiological processes[10].Recent evidences have indicated that the organic $\mathrm{Zn}$ complex has higher bioavailability than inorganic $\mathrm{Zn}$, hence is widely recommended in monogastrics[11] as well as ruminants[12].Previous results demonstrated that the dietary supplementation of organic form of $\mathrm{Zn}$ improved immune function[12], antioxidant activity[13] and overall performance[14] in different livestock species.Chen et al.[15]revealed that feed intake and both Zn digestibility and deposition in dairy cattle increased linearly with increasing Zn-Met supplementationfrom $60 \mathrm{~d}$ before expected calving until parturition. Organic form of $\mathrm{Zn}$ supplementation could enhance the milk production and decrease the somatic cell scores(SCC) in lactating cows[16]. Besides,dietary organic Zn inclusion would be beneficial toheat shock responses[14], mammary gland development[17] and metabolic responses[18] of dairy cattle during environmental heat stress.

Research on the effect of Zn-Met supplementation in high producing dairy cows under long-term environmental heat stress(LEHS) is scarce. Therefore, we aimed to observe the impact of a commercially available rumen-protected Zn-Met complex (Loprotin, Kaesler Nutrition GmbH, Cuxhaven, Germany) supplementation in early high producing Holstein cows during an LEHS period on(a) milk yield and chemical composition; (b) distinct animal behavioral indices such as rumen fill index, manure score, rumination activity, and body condition score (BCS) and (c) plasma concentrations of various metabolic, immune and oxidative stress biomarkers such as glucose, urea, cholesterol, High-density lipoprotein $(\mathrm{HDL})$, Low-density lipoprotein (LDL), triglyceride, blood enzymes i.e., alanine aminotransferase (SGPT) and aspartate aminotransferase (SGOT), non-esterified fatty acids (NEFA), beta-hydroxybutyrate (BHB), total protein, globulin, albumin, haptoglobin, calcium, Zn, total antioxidant status (TAS), malondialdehyde (MDA) and Interleukin-1 beta(IL-1B).

\section{Materials And Methods}

\section{Environmental data}

Daily data of ambient temperature $\left(\mathrm{T},{ }^{\circ} \mathrm{C}\right)$ and relative humidity $(\mathrm{RH}, \%)$ through July and August 2021 , were obtained from Fariman meteorological stations ( $35^{\circ} 42^{\prime} 0^{\prime \prime} \mathrm{N}, 59^{\circ} 50^{\prime} 0^{\prime \prime}$, Khorasan Razavi, Iran), located within $3 \mathrm{~km}$ distance of the experimental site. Daily readings were then considered by retrieving maximum daily $\mathrm{T}$ (Tmax) and $\mathrm{RH}$ value. Daily maximum $\mathrm{TH}$ was calculated, using the equation reported by Kendall et al.[19] and Ouellet et al. [20]: THI $=(1.8 \times \mathrm{Tmax}+32)-[(0.55-0.0055 \times \mathrm{RH}) \times(1.8 \times \mathrm{Tmax}-$ 26)].

This equation has been proposed for animal experiments conducting in a climate with significant day and night and season temperature[20]. 
The animal study was reviewed and approved by Institutional Animal Care Committee, Ferdowsi University of Mashhad (Mashhad, Iran; Protocol number 101984). All experimental protocols were carried out in accordance with relevant guidelines and regulations in order to minimize animal pain, suffering and distress. The study is reported following the ARRIVE guidelines (https://arriveguidelines.org).Sixtytwo high genetic merit multiparous Holstein lactating cows [ $684 \pm 16 \mathrm{~kg}$ of bodyweight, $28 \pm 7$ days in milk (DIM), parity $2.9 \pm 0.6$, milk yield $51.8 \pm 2.2 \mathrm{~kg} / \mathrm{d}$, milk fat $35 \pm 0.21 \mathrm{~g} / \mathrm{L}$, milk protein $3.23 \pm 0.05 \mathrm{~g} / \mathrm{L}$ and BCS $2.76 \pm 0.21]$ were enrolled in this experiment. Cows were balanced by 305 - $d$ previous mature-equivalent milk yield, milk yield during the 3rd and 4th weeks of lactation, DIM, and parity, then assigned to two dietary treatments ( $n=31$ per group). Animals fed a same basal diet for 7 days (5th week of lactation), then, were randomly assigned to 1 of 2 dietary treatments as control (only basal diet) or basal diet plus a rumen protected Zn-Met complex (RPZM; Loprotin, Kaesler Nutrition GmbH, Cuxhaven, Germany, as $0.131 \%$ of diet DM) beginning at 6 th week of lactation for the total period of 6 weeks. The Zn-Met complex source contains 30\% DL-Met and 7\% Zn. The ingredients and chemical composition of the experimental diets are presented in Supplementary Table S1. During the study, cows were housed in two separated free stall rows, in a barn of a commercial dairy farm, Moghofat Maleck-Fariman, with 1120 milking cows. The barn was equipped with 4 ceiling fans ( $4 X 3 \mathrm{~m}$, fan/58.5 m2), which were working for $24 \mathrm{~h} / \mathrm{d}$. Animals had free access to feed and water; diets were fed as a total mixed ration (TMR) three times per day at 0730,1630 and $2230 \mathrm{~h}$ in amounts that ensured ad libitum consumption and approximately 3 to $5 \%$ feed refusals. Dry matter intake and apparent DM digestibility were determined as proposed by Velásquez et al. [21]. Marker technique was applied to estimate fecal output and DM digestibility. Dry matter intake was then calculated by dividing fecal output by the indigestibility of DM. Samples of the diet ingredients were collected weekly, dried in a forced-air oven for $72 \mathrm{~h}$ at $55^{\circ} \mathrm{C}$, and ground using a Wiley mill to pass a 1-mm screen, then analyzed for DM and the chemical composition[22]. Dry matter was determined after $24 \mathrm{~h}$ at $95^{\circ} \mathrm{C}$ (ISO 6496). Ash was determined after $3 \mathrm{~h}$ at $550^{\circ} \mathrm{C}$ (ISO 5984). Nitrogen was assessed using the Kjeldahl method (Kjeltec 2300 Autoanalyser, Foss Tecator AB, Hoganas, Sweden) with crude protein (CP) as $N \times 6.25$. Starch content was evaluated by an anthrone-sulphuric acid method using glucose as standard and estimated as $0.9 \times$ glucose content after liberating the starch by heating in a boiling water bath in the presence of $2 \mathrm{~N} \mathrm{HCl[23].} \mathrm{For} \mathrm{neutral}$ detergent fiber (NDF) and acid detergent fiber(ADF), the method of Goering and Van Soest[24] was used.

Cows were milked three times daily at approximately 0400 and 1200 and $2000 \mathrm{~h}$. The incidence of health problems was recorded for each cow accordingly throughout the experiment and appropriate treatment was considered if necessary.

\section{Sample collection and processing}

Feed refusals of each group were measured daily and total DMI per each experimental group was monitored by difference assuming a similar DM content of feed offered and the ort. Bi-weekly (weeks 7, 9 and 11 of lactation) samples of rectal feces were provided from 20 cows per each group to evaluate fecal output, DM digestibility and feed intake. Milk yield was recorded daily, and weekly milk samples were obtained at 3 consecutive milking. Samples were preserved with 2-bromo-2-nitropropane-1,3-diol and 
analyzed for protein, fat, lactose, milk urea nitrogen (MUN), SCC, solids nonfat (SNF), and total solids content using Fourier-transform infrared spectroscopy (FT-IR; CombioScope FTIR 600 HP, Delta instruments Drachten, The Netherlands) in a commercial laboratory (Sazan Rojan Alvand CO., Iran).

Fat corrected milk (FCM) standardized to $4 \%$ fat was calculated using the following equation: FCM = [0.4 $\times$ milk yield $(\mathrm{kg})]+[15 \times$ milk fat $(\mathrm{kg})]$ and energy corrected milk $(E C M)$ was calculated as presented by Muñoz et al.[25]: ECM= [0.3246 $\times$ milk yield $(\mathrm{kg})]+[12.86 \times$ fat yield $(\mathrm{kg})]+[7.04 \times$ protein yield $(\mathrm{kg})]$. Milk energy content $\left(\mathrm{NE}_{\mathrm{L}}\right)$ was calculated using the following equation: $\mathrm{NE}_{\mathrm{L}}=[(0.0929 \times \%$ milk fat $)+(0.0563 \times$ $\%$ milk true protein $/ 0.93)+(0.0395 \times \%$ milk lactose $)] \times$ milk yield[26]

Blood was sampled bi-weekly (weeks 5, 7, 9 and 11 of lactation) from 15 cows per each group at $0800 \mathrm{~h}$ via puncture of the coccygeal vessels as proposed previously[27]. The samples were kept at room temperature and the serum was separated within $0.5 \mathrm{~h}$, then stored frozen at $-20{ }^{\circ} \mathrm{C}$ until analyses for Glucose (GOD-PAP, https://parsazmun.ir), triglycerides (GPO-POD, www.Bionik.web.com), NEFA (Colorimetric method, RANDOX, www. Randox. Com), BHB (kinetic Enzymatic method, RANDOX, www. Randox. Com), urea (Urease-GLDH method, https://parsazmun.ir), cholesterol (CHOD_POG, http://paadco.co), HDL (direct enzymatic colorimetric method, http://paadco.co), SGOT (https://parsazmun.ir), SGPT (https://parsazmun.ir), calcium (https://parsazmun.ir), Zn (Colorimetric method, RANDOX, www. Randox. Com), total protein (https://parsazmun.ir), albumin (https://parsazmun.ir), haptoglobin (ZellBio GmbH, Lonsee, Germany), TAS (Manual calouric method, RANDOX, www.Randox.com), MDA (thiobarbituric acid reactive substances assay) and IL-1B (ZellBio $\mathrm{GmbH}$, Lonsee, Germany). BothLDL and very-low-density lipoprotein (VLDL) was calculated using following equation: $L D L=$ Total cholesterol $-(H D L+V L D L), V L D L=T r i g l y c e r i d e s / 5$.

\section{Animal behavior}

Bi-weekly animal behavior indices including the time spent ruminating were recorded every 10 minutes per $24 \mathrm{~h}$ and calculated by multiplying total number of observed activities in each duration[28].Body condition score, rumen fill score and manure score were assessed bi-weekly from 7th week of lactation. Body condition score was recorded by the same operator using a 1 to 5 scale with 0.1 intervals as proposed by Ferguson et al.[29]. Both rumen fill score[30] and manure score[31] were assessed 6 times per day started $2 \mathrm{~h}$ before the morning feeding by the same operator using a 1 to 5 scale. The visual characteristics for scoring the manure and rumen fill of Holstein dairy cows were done as previously described[30, 31].

\section{Statistical Analysis}

One cow in the RPZM group was removed from the experiment at the end of the 9th week of lactation due to a physical injury. Besides, two cows in the control group were culled at the 7th and $8^{\text {th }}$ weeks of lactation due to unknown sudden drop in milk production. 
Data of milk yield and its component as well as blood biochemistry from the 5thlactation week (i.e., all animals received the similar basal diet) were used as covariate in the statistical analysis. The main aim of the statistical analysis of the experimental data was to determine the productive and metabolic responses of the cows fed the experimental diets. Data obtained weekly was statistically analyzed using the Proc Mixed procedure of SAS 9.1 (SAS Institute, Cary, NC, USA) for a completely randomized design with repeated measures included by the corresponding covariate. The model included the effects of group, week of lactation and the interaction between group and week and covariate (if necessary). Week of lactation was used as a repeated measurement, with cow within experimental groups as the subject. Experimental group, week, the interaction between treatment and week, and corresponding covariate were the fixed effects, and error was the random effect. Data of DM digestibility were averaged by cow and week of lactation, then, analyzed using a completely randomized design. Differences were considered significant at $P<0.05$, whereas tendency was determined at $0.05<P<0.1$. Data are expressed as the mean \pm standard error of means.

\section{Results}

\section{Dry matter intake, milk yield and milk composition}

Average ambient temperature, relative humidity and THI was $32.5^{\circ} \mathrm{C}, 14.5 \%$ and 75.13 , respectively. Daily similar pattern in THI was observed during the course of present experiment, hence all animals experienced an LEHS as daily THI was above 70 (Fig 1).

Dry matter intake and the productive responses of the cowswithin the experimental groups are depicted in Supplementary Table S2. There was hardly any significant effect of the experimental group and interaction between week of lactation and the group on DMl (25.85 vs. $26.68 \pm 1.3 \mathrm{~kg}$ for the control and RPZM group, respectively) and apparent total tract DM digestibility (Fig 2). Although milk yield in cows fed the Zn-Met complex was roughly $3 \mathrm{~kg}$ higher (52.9 vs. $55.1 \pm 1.21$ for the control and RPZM group, respectively), this did not reach the significant level. Cows in the RPZM group had evidently higher both milk fat and protein concentration ( $P<0.05 ; 27.3$ vs. $32.8 \pm 1.8 \mathrm{~g} / \mathrm{kg}$ and $30.1 \mathrm{vs} .31 .0 \pm 0.23 \mathrm{~g} / \mathrm{kg}$ for the control and RPZM group, respectively). One the other hand, milk lactose concentration in the control group was higher than the RPZM ( $P<0.05 ; 46.6$ vs. $45.9 \pm 0.33 \mathrm{~g} / \mathrm{kg}$ for the control and RPZM group, respectively). Milk solids concentration was evidently higher in RPZM group than the control $(P<0.01$; 113 vs. $119 \pm 1.75 \mathrm{~g} / \mathrm{kg}$ for the control and RPZM group, respectively), whereas milk SNF concentration was not affected by the dietary treatment $(P>0.05)$. Milk urea nitrogen in the animals hardly changed upon supplementation with the Zn-Met complex. Yields of fat and protein upon Zn-Met supplementation was in average $25 \%$ and $7 \%$ higher, respectively, during the course of this experiment $(P \leq 0.01)$. Fat $(4 \%)$ corrected milk as well as ECM were evidently higher ( $P=0.002$ and 0.004 , respectively) in the RPZM group compared with the control ( 42.5 vs. $48.8 \pm 1.82 \mathrm{~kg} / \mathrm{d}$ and 46.7 vs. $52.8 \pm 1.72 \mathrm{~kg} / \mathrm{d}$ for the control and $\mathrm{RPZM}$ group, respectively). Moreover, $\mathrm{NE}_{\mathrm{L}}$ was significantly higher in animals fed the $\mathrm{Zn}$-Met complex source than the control $(P=0.024 ; 91.1$ vs. $100 \pm 2.71 \mathrm{Mcal} / \mathrm{d}$ for the control and RPZM group, 
respectively). Animals in the RPZM group had significantly lower $(P=0.001)$ SCC during the experimental period in comparison with their counterparts in the control group.

\section{Body condition score and animal behavioral indices}

Means \pm standard error of means of rumination time per $24 \mathrm{~h}$ for each experimental group is presented in Fig $3 \mathrm{~A}$, in which no significant differences between the groups and lactation week was observed. The effect of diets on BCS of the animals throughout the experimental lactation weeks is depicted in Fig 3B. Initial BCS of all animals located in the groups were similar and hardly a significant effect of the experimental groups was observed within the study.

The data of manure score and rumen fill score are shown in Fig 4A and B, respectively. Manure score was unaffected by the experimental groups. However, week of lactation caused a decrease in the rumen fill score within the experimental period $(P<0.05)$. Animals had generally lower rumen fill score as the experimental lactation weeks progressed.

\section{Blood serum biomarkers}

Blood serum composition of the cows fed the experimental diets during an LEHS period are shown in Supplementary Table S3.In the current study, the circulating glucose and urea concentrations of the animals between experimental groups were not significantly different. Data regarding the concentration of blood triglycerides, BHB and NEFA showed hardly any significant difference between the experimental groups $(P>0.05)$. Blood serum cholesterol as well as LDL concentration showed tendency to be higher $(P=0.1$ and $P=0.06$, respectively) upon dietary supplementation of the Zn-Met complex during the experimental period. However, the circulating HDL and VLDL concentrations were not significantly different between the experimental groups. The circulating concentration of blood enzymes including SGOT and SGPT were not significantly changed by the experimental diet during the course of this study $(P>0.05)$. There was a clear effect of experimental groups and week of lactation on blood serum $\mathrm{Zn}$ concentration (Fig 5A; $P=0.038$ ). Cows fed basal diet supplemented with the Met-Zn complex source had evidently higher blood serum Zn concentration than those of the control (74.4 vs. $86.4 \mathrm{ug} / \mathrm{dL}$ for the control and RPZM group, respectively). The serum calcium concentration in the animals fed the experimental diets supplemented with the Zn-Met complex was clearly $(P<0.01)$ higher in comparison with the control (10.3 vs. $11.3 \pm 0.23 \mathrm{mg} / \mathrm{dL}$ for the control and RPZM group, respectively; Fig 5B). In the present study, Zn-Met supplemented cows tended to have higher albumin concentration compared with those in the control group (Fig $6 \mathrm{~A} ; \mathrm{P}=0.08$ ). Besides, blood serum haptoglobin concentration evidently decreased $(P=0.001)$ in cows fed experimental diet with the Zn-Met supplementation ( 267 vs. $240 \pm$ $10.53 \mathrm{mcg} / \mathrm{ml}$ for the control and RPZM group, respectively; Fig 6B). The outcome of this work indicated that the circulating IL-1B concentration in animals supplemented with the Zn-Met complex was markedly $(P=0.001)$ lower in comparison with the control group (76.83 vs. $60.01 \pm 3.4 \mathrm{ng} / \mathrm{Lfor}$ the control and RPZM group, respectively; Fig 6C). Blood serum concentration of MDAand TAS of animals in both experimental groups are shown in Fig 7A and B, respectively. Dairy cattle in the RPZM group had significant $(P=0.017)$ higher blood TAS along with lower MDA concentration $(P=0.08)$ through the 
experimental period compared with their counterparts in the control group $(0.62 \mathrm{vs} .0 .68 \pm 0.02 \mathrm{mmol} / \mathrm{L}$ and 2.01 vs. $1.76 \pm \mathrm{nmol} / \mathrm{L}$ for the control and RPZM group, respectively).

\section{Discussion}

Supplementing the diet of dairy cows in the current study with the Zn-Met complex did not show any effect on the feed intake of the animals. Therefore, it could be postulated that the negative effect of Met on DMI is negligible when a Zn-Met complex is used in the diet of lactating cows under heat stress condition.Previous reports showed that an increase in catabolism of AA resulted in elevation of core body temperature and greater body protein turnover, which is associated with higher heat increment [32]. Increase in deamination of AA, resulted from excess intake of the AA relative to the animal requirements, would contribute to losses in both DMI and production in heat stressed animals. Robinson et al. [33] infused Met, in excess of the animal requirement, and reported a depression of feed intake in the animals. They concluded that observed reduced DMI might be due to imbalanced supply of AA. Kassube et al. [34] evaluated the effect of essential AA on DMI and milk production in lactating dairy cows exposed to short-term heat stress conditions. The authors revealed that heat stress decreased DMI by $1.5 \mathrm{~kg} / \mathrm{d}$ compared with those animals in the thermoneutral condition, while in animals received Met as well as branched-chain amino acidsthe DMI decreased by $0.7 \mathrm{~kg} / \mathrm{d}$.

Outcome of the current experiment pinpointed an evident influence of feeding Zn-Met complex on lactation performance, as evidenced by increased both milk fat and protein concentrations and yields. It is important to focus on dairy cow diet formulation to cover animal's metabolisable Met in order to enhance milk protein and fat production. Recent data showed the positive impact of feeding rumenprotected Met sources on milk protein concentration [3] as well as yield [6] of dairy cows exposed to LEHS. However, the influence of rumen-protected Met products in previous research have been to some degree inconsistent, with considerable variations for particular lactation performance responses [35]. The outcome of this study was in line with previous work[3] indicating an increase in milk fat yield by enhancing post-ruminal Met supply. Batistel et al. [4] demonstrated that $0.17 \mathrm{~kg} / \mathrm{d}$ more milk fat was produced in early lactating Holstein cows upon increasing the matabolisable Met concentration. Besides, Patton [36] reported that cows with deficient Met responded to rumen-protected Met supplementation with greater milk fat yield. Apparently, Met has the potential to alter mRNA expression of selected lipogenic genes in bovine mammary cells [37]. Nevertheless, the impact of feeding rumen-protected Met on regulation of mammary fatty acid synthesis merits further investigation. Other plausible reason for positive effect of feeding rumen-protected Met on milk fat concentration and yield is related to alleviation of negative energy balance in dairy cows through improvement in animal's metabolic status and immune system[4]. Kellogg et al. [38] reported that feeding Zn-Met, relative to inorganic form of Zn, increased the milk composition yield in dairy cattle. Nayeri et al. [39]studied different ratio of zinc sulfate to zinc amino acid complex in pre- and post-partum Holstein cows. They concluded that supplementing organic zinc depicts positive effects on production parameters in dairy cows. The current experiment was able to reveal the positive impact of feeding rumen protected $\mathrm{Zn}$-Met on $\mathrm{FCM}, \mathrm{ECM}$ and $\mathrm{NE}_{\mathrm{L}}$ in dairy cows 
exposed to LEHS. This may explain the value of a supplementary mixture of $\mathrm{Zn}$ and Met in animals. However, several studies showed an absence of such positive impact of Zn [14] or Met [6,34] on FCM and ECM. These non-significant responses could be due to different factors e.g., experimental design, number of animals in each treatment, animal homogeneity in each group and in-group variations among the animals. Recently the term "residual feed intake" (RFI) has been introduced as a tool to evaluate feed efficiency in dairy cow, as RFI is independent of production level [40]. Residual feed intake is calculated as the difference between cow's actual feed intake and its predicted feed intake calculated from milk production, metabolic body weight and change of body weight [41]. Lactating cow with a negative RFI consumes less than expected for its level of production and thus is more efficient. The biological mechanisms elaborating differences in RFI among dairy cows are not well-defined [41]; however, it has been shown that protein turnover and tissue metabolism has the most impact on RFI in finishing beef steers [42]. Hence, it could be postulated that the positive effect of supplementary Zn-Met complex, in the current study, on lactation performance may be achieved through optimizing body protein turnover and milk protein generation leading to a better RFI, as DMI between the groups was similar.On the other hand, current experimental dietary Zn provided by a complex of Zn-Met showed potent impact to alleviate the negative effects of heat stress on both fat and energy corrected milk. Zinc is able to maintain critical body functions including epithelial integrity and tissue function [43]. Abuajamieh et al. [44] revealed that dietary inclusion of organic $\mathrm{Zn}$ lead to improved intestinal barrier function during heat stress.

Environmental heat stress increase the permeability of the mammary epithelium of lactating dairy cows, while dietary $\mathrm{Zn}$ helps to improve the performance along with maintainingthe permeability of the mammary epithelium and mammary epithelial integrity [14]. Therefore, AA and energy may shift to milk synthesis rather to restore proper epithelial integrity. Our data confirmed the findings of Sobhanirad et al. [45], which evaluated the effect of a mixture of Zn-Met and inorganic form of Zn supplement in lactating cow diets and reported lower SCC in the treatment group compared with the control. Pate et al. [2] concluded targeting a more balanced AA diet in dairy cattle during heat stress, via dietary rumenprotected Met supplementation, maintains lower milk SCC in the animals. The current outcome imply that animals fed the Zn-Met complex could be less prone to experience mammary gland disorders, which hinder the productivity and longevity of dairy cows.

In the current study, either the experimental diets or the weeks of lactation did not show any evident influence on animals BCS. Robinson et al. [46] studied the effect of rumen protected Met on performance and BCS changes in Holstein cows. They concluded that cows supplemented with rumen-protected Met had similar BCS in relation to the other experimental groups. Therefore, most energy intake was used for output of energy in the milk rather changes in body weight and BCS.Rumination time is mostly influenced by the physically effective fiber [28], which resulted in increasing the surface area of feed particle. Besides, the time that cows spend chewing might be a valuable management tool for detecting health problems and optimizing the herd heath status [28], as monitoring rumination time is easier than monitoring DMI. In the present study, mean daily rumination time of the cows located in the experimental was above the threshold of early lactating Holstein cows [28] indicating that animals were in a good health status.In the current work, cows had rumen fill scores that are acceptable for high producing 
Holstein cows. However, the rumen fill score decreased with progress of the experimental weeks. Rumen fill score is mainly influenced by the feed intake, particularly by the proportion of roughage in the diet [30]. Hence, it is believed that the animals used in this study had sufficient DMI and relatively well-balanced metabolic status.

Circulating calcium concentration was higher in animals fed the commercial Zn-Met source during LEHS. The effect of dietary CP on flux and metabolism of calcium has been widely considered. Previous research in Jersey cows revealed that by increasing the protein intake during the dry period, lowernumber of milk fever incidences was observed [47]. The authors proposed that circulating calcium concentration and metabolism might be affected by protein intake in dairy cows. Nevertheless, the information on the impact of individual AA feeding is scarce.de Moraes et al. [48] examined the impact of dietary Met concentration on performance, localization and expression of the epithelial calcium transporter channels of digestive and reproductive system in laying quails under heat stress. The authors pinpointed that negative effect of heat stress was minimized when the birds took Met concentration at $120 \%$ requirement level. Besides, the epithelial calcium transporters were altered; hence, animals required less calcium absorption and re-absorption due to more available calcium upon Met supplementation.Both Met and $\mathrm{Zn}$ are important factors for whole body protein synthesis, specially binding proteins [48]. However, a combination of $\mathrm{Zn}$ and Met seems more effective. Therefore, a complex of Zn-Met may influence the blood calcium flux by increasing the synthesis of binding protein and optimizing epithelium structure, which fascinate the absorptive and re-absorptive potential of calcium. Horst et al. [49] argued that changes in circulating calcium is simply a reflective of animal homothetic adjustments and immune activation. The authors mentioned hypocalcemia might occur as a reflection of inflammation and health status of the animal, which is associated with poor performance responses. It could be postulated that healthy cows under heat stress encompass better metabolic pattern as well as suffering less from acute inflammation. Moreover, a positive immune system resulted in normal calcium metabolism demonstrating a non-hypocalcaemia status [49]. Circulating Zn concentration in animals fed the dietary Zn-Met complex was clearly higher. A consequence of an increased $\mathrm{Zn}$ absorption in the gastrointestinal tract would be higher mineral concentration in the blood as observed in the current study. Previous reports indicated that $\mathrm{Zn}$ bioavailability is increased in dairy cows fed experimental diets with organic forms of $\mathrm{Zn}[16]$. This would lead to improved productive and metabolic responses in the animals $[12,39]$.

In dairy cows under energy deficiency, a mobilization of body fat reserves occurs and thus the concentration of NEFA increases in the blood [50]. A non-significant difference in blood bioenergetics metabolites, as observed herein, could imply that cows in both experimental groups were in a relatively balanced energy status. Metabolic alteration in liver function is an important aspect in high producing dairy cows, particularly during periods of heat stress. An elevation of SGPT and SGOT may indicate an accumulation of NEFA transported from blood to hepatocytes [51], which in turn enablesthe liver to reduce the hepatocytes damages and moderate its metabolic function. Non-significant differences in blood enzyme concentration observed in this experiment could suggestthat animals in both experimental groups maintained healthy liver function. 
Severity of inflammation in dairy cattle can be characterized by an increased circulating concentration of haptoglobin, as a positive acute phase protein, and lower biosynthesis of albumin as a negative acute phase protein [52]. Haptoglobin levels was shown to be evidently higher in non-healthy dairy cows relative to healthy animals [53]. Previous studies indicated elevated levels of haptoglobin as early as $5 \mathrm{~d}$ postpartum in cows developing subclinical endometritis in later stages post-calving [54]. These findings provide evidences that blood haptoglobin concentration, as a metabolic signal, is associated with a systemic inflammatory responses and liver function[55]. Lower haptoglobin levels in the RPZM group indicated that animals were less prone to experience acute inflammation, thereby being able to maintain their health status during the LEHS period. Heat stress alters the use of AA in metabolic tissues by decreasing blood AA concentration and increasing nitrogen excretion. This could limit the function of AA supply to the liver and mammary gland, resulting an increased inflammatory response. Boosting postruminal Met supply during heat stress might lead to a lower acute inflammation status, which in turn supports the overall health of the animals. Bertoni et al. [52] found that cows with high indexes of inflammation produced $20 \%$ less milk during the first month of lactation than those in the lower indexed category. Our results confirmed that dietary supplementationof high producing dairy cow with Zn-Met complex during LEHS would have a positive effect on animal health status, ultimately improving the lactation performance of animals. Lopreiato et al. [56] using an in vitro experiment showed that Met at lowest concentration had a potential to downregulate the entire repertoire of innate inflammatory genes e.g., IL-1B and -6, proposing reduced cellular inflammation. IL-1 locates as either secreted or membranebound form in many cell types e.g., hematopoietic and non-hematopoietic cells. Expression of IL-1 could be triggered by various stimuli, such as inflammation and stress, which ensures host protection and pathogen control by driving cell-cell cross interaction[57]. Mehla et al. [58] revealed that IL1 gene expression increased during short exposure periods of heat stress, yet decreased in the recovery phase. Previous works have shown higher levels of different cytokines e.g., IL-1B, IL-6, and tumor necrosis factorain the heat stress-exposed cows, which suggests the possibility of an inflammatory condition resulting from the heat stress environment [59]. Lower serum IL-1B levels upon Zn-Met complex supplementation in the current experiment indicated that animals were able to adjust more efficiently with the potent negative impacts of the thermal stress on dairy cows immune system.

Lower MDA concentration in dairy cows fed with Met-Zn complex observed herein, pinpoints a reduction in lipid peroxidation in these animals. Oxidative stress is an imbalance of antioxidants and oxidative molecules, such as reactive oxygen species and lipid peroxides. Malondialdehyde exerts cytotoxic effects, since it oxidizes DNA, proteins and lipids and establishes cross-links between AA side groups. Therefore, MDA detection implies systemic effects of persisting oxidative stress. Previous reports revealed that heat stress exacerbates oxidative stress and reactive oxygen species production in dairy cows [60]. Results of this study were in line with previous works indicating lower levels of lipid peroxidation and improved antioxidant capacity in mid-lactating dairy cows fed Met derivatives [61]. Increasing post-ruminal Met in ewes resulted in evident decline in MDA plasma levels as observed in the current experiment [62]. The outcome of this experiment was in contrary to previous reports, in which supplementing diet of dairy cows with Zn-Met did not show any significant effect on blood MDA or TAS levels [63]. Oxidative stress is 
one of the contributing factors to the impairment of the immune responses during an environmental stress. Hence, alteration of oxidative metabolites in cows would influence the cytokine production [64]. Outcome of the current experiment indicates that dairy cows benefit from feeding a higher bioavailable source of $\mathrm{Zn}$ and Met through reactivating their immune system and expressing an adaptive response.

\section{Conclusion}

Overall, a rumen-protected Zn-Met complex dietary inclusion ameliorates the production performance of dairy cows during the period of LEHS. Higher productivity in the animals seems to be partly driven by lower inflammation and improved anti-oxidative capacity as observed bythe selected blood biomarkers.Environmental heat stress can initiate oxidative stress in the animals, deteriorating their productive responses and health status. Zn-Met complex seems to alleviate those potent negative impacts of oxidative stress.Besides, lower haptoglobin levels along with decreased IL-1B serum concentration in the Zn-Met supplemented dairy cattle suggest that animals would suffer less from acute or chronic diseases, allowing them to maintain or even improve their productive capacity during LEHS.Elaboration ofthe detailed mechanism merits further investigation. A compelling idea would be to determine the influence of the rumen-protected Zn-Met source during transition period, where dairy cows liver function and immune system is greatly challenged.

\section{Declarations}

\section{Author's contribution}

M.D.M. and H.K.conceived and designed the study and wrote the main draft of the manuscript.M.D.M. designed the graphs and tables. H.K. conducted the animal experiment and sample collection.A.G. assisted with part of the sample collection and analysis and conducted the statistical analysis. A.V. conducted the blood biochemistry analysis. R.J. and S.D.M. contributed to designing the study. All authors reviewed and approved of the final manuscript.

\section{Acknowledgment}

Financial support for this experiment was provided in part by Ferdowsi University of Mashhad (Grant number: 9305) and Kaesler Nutrition $\mathrm{GmbH}$ (Cuxhaven, Germany). The authors acknowledge the Moghofat Maleck Dairy Farm staff for help with the animal management.

\section{Data Availability}

The datasets used and/or analyzed during the current study are available from the corresponding author on reasonable request.

\section{Competing interests}


RJ and SDM are employed by Kaesler Nutrition $\mathrm{GmbH}$. This does not alter the authors' adherence to journal's policies on sharing data and materials. The remaining authors declare that the research was conducted in the absence of any commercial or financial relationships that could be construed as a potential conflict of interest.

\section{References}

1. Vitali, A. et al. Seasonal pattern of mortality and relationships between mortality and temperaturehumidity index in dairy cows. J. Dairy Sci. 92, 3781-90 (2009).

2. Pate, R. T., Luchini, D., Murphy, M. R. \&Cardoso, F. C. Effects of rumen-protected methionine on lactation performance and physiological variables during a heat stress challenge in lactating Holstein cows. J. Dairy Sci. 103, 2800-2813 (2020).

3. Osorio, J. S., Ji, P., Drackley, J. K., Luchini, D. \&Loor, J. J. Supplemental Smartamine M or MetaSmart during the transition period benefits postpartal cow performance and blood neutrophil function. $J$. Dairy Sci.96, 6248-6263 (2013).

4. Batistel F. et al. Ethyl-cellulose rumen-protected methionine alleviates inflammation and oxidative stress and improves neutrophil function during the periparturient period and early lactation in Holstein dairy cows. J. Dairy Sci. 101, 480-490 (2018).

5. Métayer, S. et al. Mechanisms through which sulfur amino acids control protein metabolism and oxidative status. J. Nutr. Biochem. 19, 207-215 (2008).

6. Toledo, M. Z. et al. Effects of feeding rumen-protected methionine pre- and postpartum in multiparous Holstein cows: Lactation performance and plasma amino acid concentrations. J. Dairy Sci. 104, 7583-7603 (2021).

7. Dong X, Zhou Z, Saremi B, Helmbrecht A, Wang Z, Loor JJ. Varying the ratio of Lys:Met while maintaining the ratios of Thr:Phe, Lys:Thr, Lys:His, and Lys:Val alters mammary cellular metabolites, mammaliantarget of rapamycin signaling, and gene transcription. J. Dairy Sci.2018; 101: 17081718.

8. Predieri, G. et al. Metal chelates of 2-hydroxy-4-methylthiobutanoic acid in animal feeding. Part 2: further characterizations, in vitro and in vivo investigations. J. Inorg. Biochem.99, 627-636 (2005).

9. Zhou, Z. et al. Better postpartal performance in dairy cows supplemented with rumen-protected methionine compared with choline during the peripartal period. J. Dairy Sci. 99, 8716-8732 (2016).

10. Siciliano-Jones, J. L., Socha, M. T., Tomlinson, D. J. \&De-Frain, J. M. Effect of trace mineral source on lactation performance, claw integrity, and fertility of dairy cattle. J. Dairy Sci. 91, 1985-1995 (2008).

11. Zhang, Y. et al. Effects of zinc sources and levels of zinc amino acid complex on growth performance, hematological and biochemical parameters in weanling pigs. Asian-Australas. J Anim. Sci.31, 1267-1274 (2018).

12. Nemec, L. M. et al. Immune responses in lactating Holstein cows supplemented with $\mathrm{Cu}, \mathrm{Mn}$, and $\mathrm{Zn}$ as sulfates or methionine hydroxy analogue chelates. J. Dairy Sci.95, 4568-4577 (2012). 
13. Richards, J. D., Zhao, J., Harrell, R. J., Atwell, C. A. \&Dibner, J. J. Trace mineral nutrition in poultry and swine. Asian-Australas. J. Anim. Sci.23, 1527-1534 (2010).

14 . Weng, $X$. et al. Effects of heat stress and dietary zinc source on performance and mammary epithelial integrity of lactating dairy cows. J. Dairy Sci. 101, 2617-2630 (2018).

15. Chen, F. et al. Effects of prepartum zinc-methionine supplementation on feed digestibility, rumen fermentation patterns, immunity status, and passive transfer of immunity in dairy cows. J. Dairy Sci. 103, 8976-8985 (2020).

16. Cope, C. M., Mackenzie, A. M., Wilde, D. \&Sinclair, L. A. Effects of level and form of dietary zinc on dairy cow performance and health. J. Dairy Sci.92, 2128-2135 (2009).

17. Orellana Rivas, R. M. et al. Effects of evaporative cooling and dietary zinc source on heat shock responses and mammary gland development in lactating dairy cows during summer. J. Dairy Sci.104, 5021-5033 (2021).

18. Horst, E. A. et al. Effects of dietary zinc source on the metabolic and immunological response to lipopolysaccharide in lactating Holstein dairy cows. J. Dairy Sci.102, 11681-11700 (2019).

19. Kendall, P. E., Tucker, C. B., Dalley, D. E., Clarck, D. A. \& Webster, J. R. Milking frequency affects the circadian body temperature rhythm in dairy cows. Livest. Sci. 117, 130-138 (2008).

20. Ouellet, V., Cabrera, V. E., Fadul-Pacheco, L. \&Charbonneau, E. The relationship between the number of consecutive days with heat stress and milk production of Holstein dairy cows raised in a humid continental climate. J. Dairy Sci.102, 8537-8545 (2019).

21. Velásquez, A. V. et al.Evaluating internal and external markers versus fecal sampling procedure interactions when estimating intake in dairy cows consuming a corn silage-based diet. J. Dairy Sci.101, 5890-5901 (2018).

22. AOAC International. Official Methods of Analysis17th ed. (AOAC International, 2000).

23. Cone, J.Degradation of starch in feed concentrates by enzymes, rumen fluid and rumen enzymes. J. Sci. Food Agric. 54, 23-34 (1991).

24. Goering, H. K. \&Van Soest, P. J. Forage fiber analysis (apparatus, reagents, procedures, and some applications). In: Agricultural Handbook No. 379. (USDA-ARS, 1970).

25. Muñoz, C., Hube, S., Morales, J. M., Yan, T. \& Ungerfeld, E. M. Effects of concentrate supplementation on enteric methane emissions and milk production of grazing dairy cows. Livest. Sci. 175, 37-46 (2015).

26. NRC (National Research Council). Nutrient Requirements of Dairy Cattle 7th rev. ed. (National Academy Press, 2001).

27. Danesh Mesgaran, M., Kargar, H., Danesh Mesgaran, S. \&Javadmanesh, A. PeripartalRumenProtected L-CarnitineManipulates the Productive and Blood Metabolic Responses in High-Producing Holstein Dairy Cows. Front. Vet. Sci. 8, 769837; 10.3389/fvets.2021.769837 (2021).

28. Beauchemin, K. A. Invited review: Current perspectives on eating and rumination activity in dairy cows. J. Dairy Sci. 101, 4762-4784 (2018). 
29. Ferguson, J. D., Galligan, D. T. \&Thomsen, N. Principal descriptors of body condition score in Holstein cows. J. Dairy Sci. 77, 2695-2703 (1994).

30. Burfeind, O. et al. Technical note: Evaluation of a scoring system for rumen fill in dairy cows. J. Dairy Sci. 93, 3635-3640 (2010).

31. Wilkerson, V. A., Mertens, D. R. \&Casper, D. P. Prediction of excretion of manure and nitrogen in Holstein dairy cattle. J. Dairy Sci. 80, 3193-3204 (1997).

32. Noblet, J., Le Bellego, L., van Milgen, J. \&Dubois, S. Effects of reduceddietary protein level and fat addition on heat production and nitrogen andenergy balance in growing pigs. J. Anim. Res. 50, 2272 (2001).

33. Robinson, P. H. et al. Influence of abomasal infusion of high levels of lysine or methionine, or both, on ruminal fermentation, eating behavior, and performance of lactating dairy cows. J. Anim. Sci. 78, 1067-1077 (2000).

34. Kassube, K. R., Kaufman, J. D., Pohler, K. G., McFadden, J. W. \&Ríus, A. G. Jugular-infused methionine, lysine and branched-chain amino acids does not improve milk production in Holstein cows experiencing heat stress. Animal.11, 2220-2228 (2017).

35. Zanton, G. I., Bowman, G. R., Vazquez-Anon, M. \&Rode, L. M. Meta-analysis of lactation performance in dairy cows receiving supplemental dietary methionine sources or postruminal infusion of methionine. J. Dairy Sci. 97, 7085-7101 (2014).

36. Patton, R. A. Effect of rumen-protected methionine on feed intake, milk production, true milk protein concentration, and true milk protein yield, and the factors that influence these effects: A metaanalysis. J. Dairy Sci. 93, 2105-2118 (2010).

37. Li, S. et al. Essential amino acid ratios and mTOR affect lipogenic gene networks and miRNA expression in bovine mammary epithelial cells. J. Anim. Sci. Biotechnol. 7, 44; 10.1186/s40104-0160104-x (2016).

38. Kellogg, D. W., Tomlinson, D. J., Socha, M. T. \&Johnson, A. B. Review: Effects of zinc methionine complex on milk production and somatic cell count of dairy cows: Twelve-trial summary. Prof. Anim. Sci. 20, 295-301 (2004).

39. Nayeri, A. et al.Effect of the ratio of zinc amino acid complex to zinc sulfate on the performance of Holstein cows. J. Dairy Sci. 97, 4392-4404 (2014).

40. Li, B. et al. Genomic prediction of residual feed intake in US Holstein dairy cattle. J. Dairy Sci. 103, 2477-2486 (2020).

41. Pott,s S. B., Boerman, J. P., Lock, A. L., Allen, M. S. \& VandeHaar, M. J. Residual feed intake is repeatable for lactating Holstein dairy cows fed high and low starch diets. J. Dairy Sci. 98, 47354747 (2015).

42. Richardson, E. C., Herd, R. M., Archer, J. A. \&Arthur, P. F. Metabolic differences in Angus steers divergently selected for residual feed intake. Aust. J. Exp. Agric. 44, 441-452 (2004).

43. Pearce, S. C. et al. Dietary organic zinc attenuates heat stress-induced changes in pig intestinal integrity and metabolism. J. Anim. Sci. 93, 4702-4713 (2015). 
44. Abuajamieh, M. et al. The effects of zinc amino acid complex on biomarkers of gut integrity and metabolism in heat-stressed steers. J. Anim. Sci.94, 564 (2016).

45. Sobhanirad, S., Carlson, D. \&Bahari Kashani, R. Effect of zinc methionine or zinc sulfate supplementation on milk production and composition of milk in lactating dairy cows. Biol. Trace. Elem. Res. 136, 48-54 (2010).

46. Robinson, P. H. et al. Ruminally Protected Lysine or Lysine and Methionine for Lactating Dairy Cows Fed a Ration Designed to Meet Requirements for Microbial and Postruminal Protein. J. Dairy Sci. 81, 1364-1373 (1998).

47. Wang, C. \&Beede, D. K. Effects of Supplemental Protein on Acid-Base Status and Calcium Metabolism of Nonlactating Jersey Cows. J. Dairy Sci. 73, 3178-3186 (1990).

48. de Moraes, L. R. et al. Methionine supplementing effects on intestine, liver and uterus morphology, and on positivity and expression of Calbindin-D28k and TRPV6 epithelial calcium carriers in laying quail in thermoneutral conditions and under thermal stress. PLOS ONE16, e0245615; 10.1371/journal.pone.0245615 (2021).

49. Horst, E. A., Kvidera, S. K. \&Baumgard, L. H. Invited review: The influence of immune activation on transition cow health and performance-A critical evaluation of traditional dogmas. J. Dairy Sci.104, 8380-8410 (2021).

50. Meyer, J. et al. Dietary L-carnitine supplementation modifies the lipopolysaccharide-induced acute phase reaction in dairy cows. Animals.11, 136; 10.3390/ani11010136 (2021).

51. Stuber, V. A., Grummer, R. R., Bertics, S. J. \& Reynolds, C. K. Effect of prepartum propylene glycol administration on periparturient fatty liver in dairy cows. J. Dairy Sci. 76, 2931-2939 (1993).

52. Bertoni, G., Trevisi, E., Han, X. \&Bionaz, M. Effects of inflammatory conditions on liver activity in puerperium period and consequences for performance in dairy cows. J. Dairy Sci. 91, 3300-3310 (2008).

53. Stefanska, B. et al. Subacute ruminal acidosis affects fermentation and endotoxin concentration in the rumen and relative expression of the CD14/TLR4/MD2 genes involved in lipopolysaccharide systemic immune response in dairy cows. J. Dairy Sci.101, 1297-1310 (2018).

54. Brodzki, P. et al. Inflammatory cytokines and acute-phase proteins concentrations in the peripheral blood and uterus of cows that developed endometritis during early postpartum. Theriogenology. $\mathbf{8 4}$, 11-18 (2015).

55. Rius, A. G. Invited Review: Adaptations of protein and amino acid metabolism to heat stress in dairy cows and other livestock species. AAS. 35, 39-48 (2019).

56. Lopreiato, V. et al. Inflammation and oxidative stress transcription profiles due to in vitro supply of methionine with or without choline in unstimulated blood polymorphonuclear leukocytes from lactating Holstein cows. J. Dairy Sci. 102, 10395-10410 (2019).

57. Di Paolo, N. C. et al. Interdependence between Interleukin-1 and Tumor Necrosis Factor Regulates TNF-Dependent Control of Mycobacterium tuberculosis Infection. Immunity. 43, 1125-1136 (2015). 
58. Mehla, K. et al. Genome-wide analysis of the heat stress response in Zebu (Sahiwal) cattle. Gene. 533, 500-507 (2014).

59. Chen, S.et al. Exposure to heat-stress environment affects the physiology, circulation levels of cytokines, and microbiome in dairy cows. Sci. Rep. 8, 14606; 10.1038/s41598-018-32886-1 (2018).

60. Bernabucci, U., Ronchi, B., Lacetera, N. \&Nardone, A. Markers of oxidative status in plasma and erythrocytes of transition dairy cows during hot season. J. Dairy Sci. 85, 2173-2179 (2002).

61. Liang, S. L. et al. Effect of N-acetyl-I-methionine supplementation on lactation performance and plasma variables in mid-lactating dairy cows. J. Dairy Sci.102, 5182-5190 (2019).

62. Mavrommatis, A. et al. Effects of Supplementing Rumen-Protected Methionine and Lysine on Milk Performance and Oxidative Status of Dairy Ewes. Antioxidants. 10, 654; 10.3390/antiox10050654 (2021).

63. Cai, J. et al. Nano-sized zinc addition enhanced mammary zinc translocation without altering health status of dairy cows. Anim. Nutr. 7, 1024-1030 (2021).

64. Sordillo, L. M. \&Raphael, W. Significance of metabolic stress, lipid mobilization, and inflammation on transition cow disorders. Vet. Clin. North. Am. Food. Anim. Pract. 29, 267-278 (201

\section{Figures}




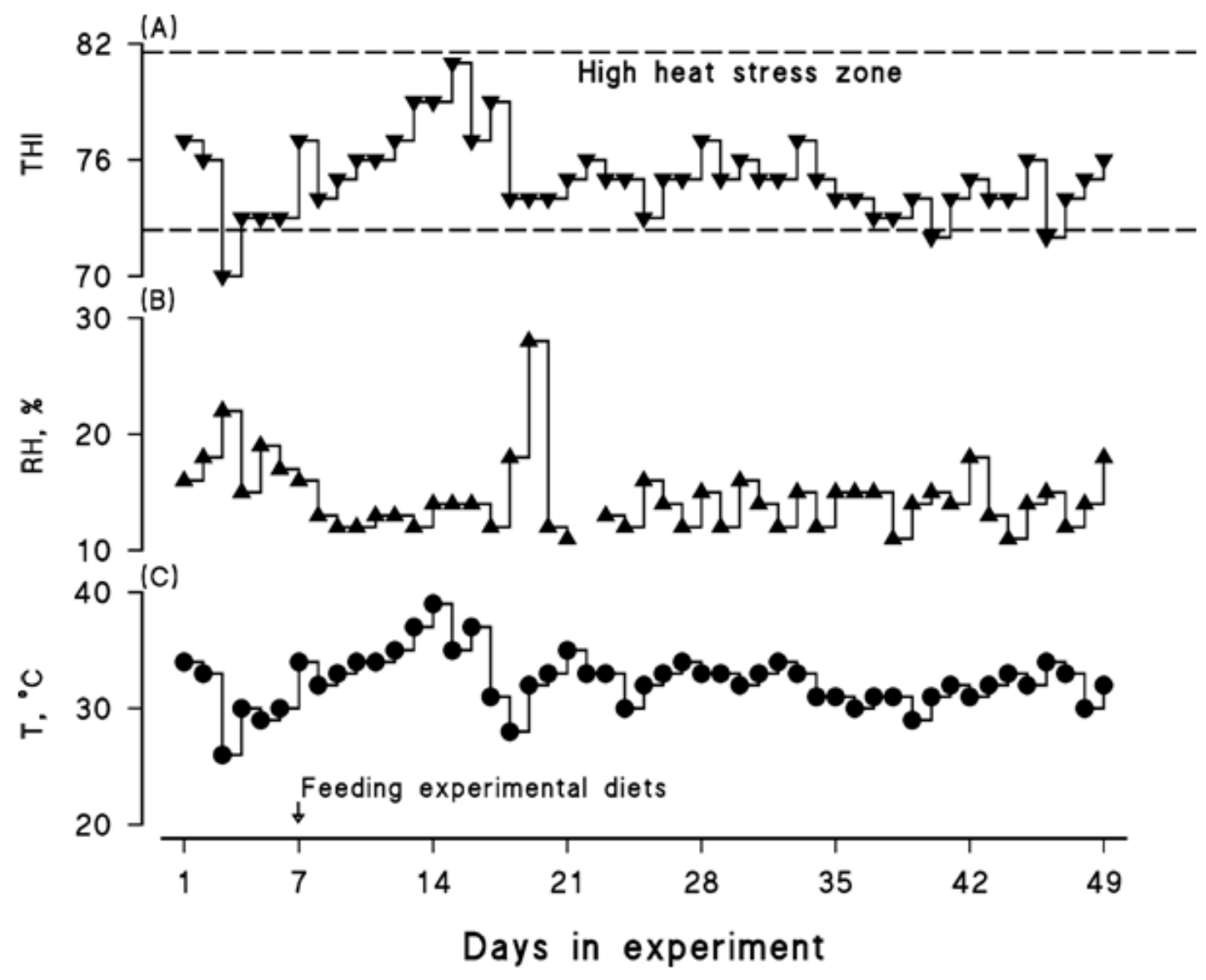

Figure 1

Collected meteorological data and computed temperature-humidity indexCalculated temperaturehumidity index ( $\mathrm{THI}$; panel $\mathrm{A}$ ) along with recorded relative humidity $(\mathrm{RH}, \%$; panel $\mathrm{B})$ and maximum ambient temperature $\left(\mathrm{T},{ }^{\circ} \mathrm{C}\right.$; panel $\mathrm{C}$ ) during the course of the experiment (July-August, 2021).Daily maximum THI was calculated, using the following equation: THI $=(1.8 \times \operatorname{Tmax}+32)-[(0.55-0.0055 \times$ $\mathrm{RH}) \times(1.8 \times \mathrm{Tmax}-26)]$. 


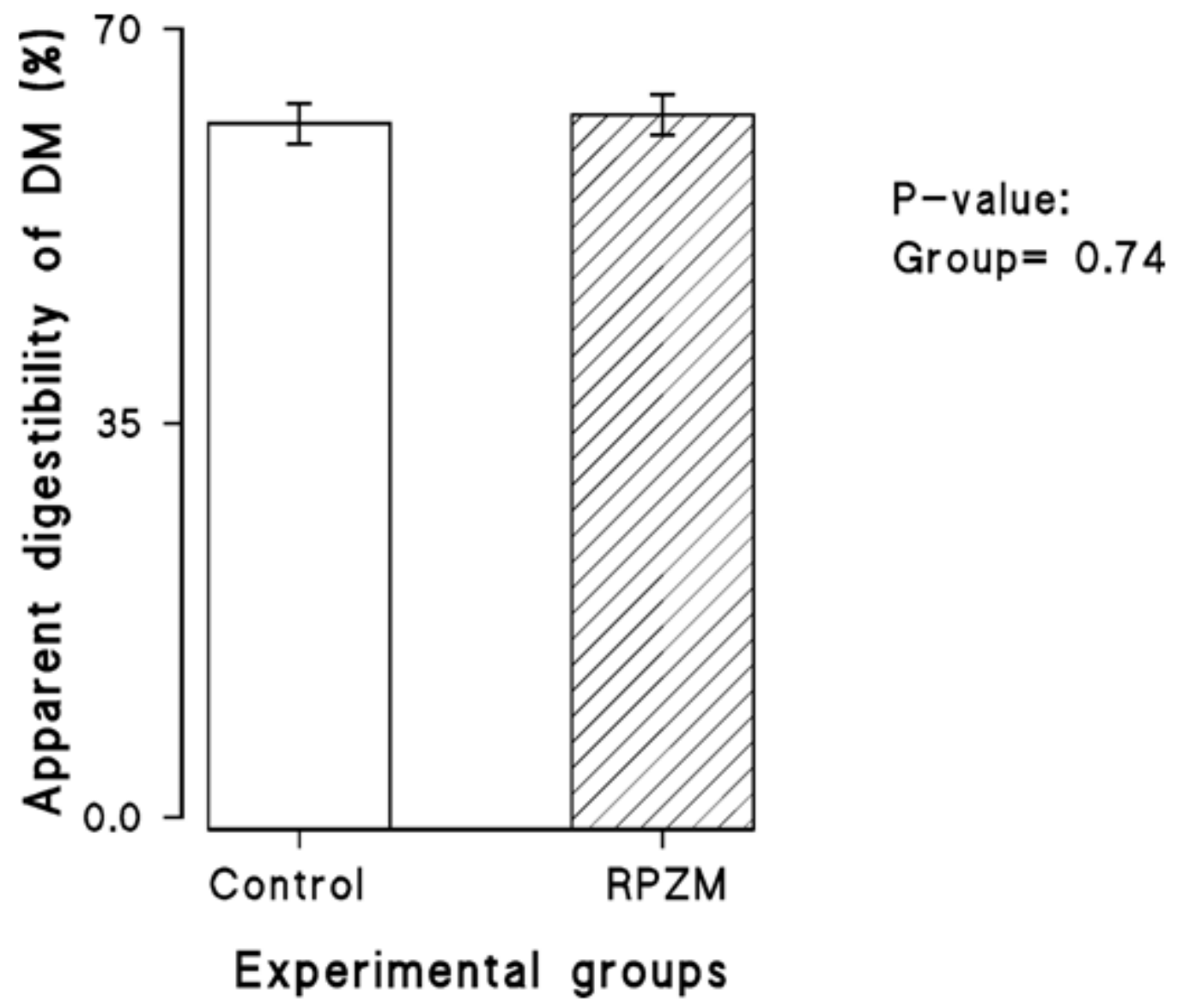

Figure 2

Apparent dry matter digestibility Apparent digestibility of dry matter in high producing Holstein cows supplemented without (Control) or with rumen-protected Zinc-Methionine complex (RPZM) during a longterm environmental heat stress. 


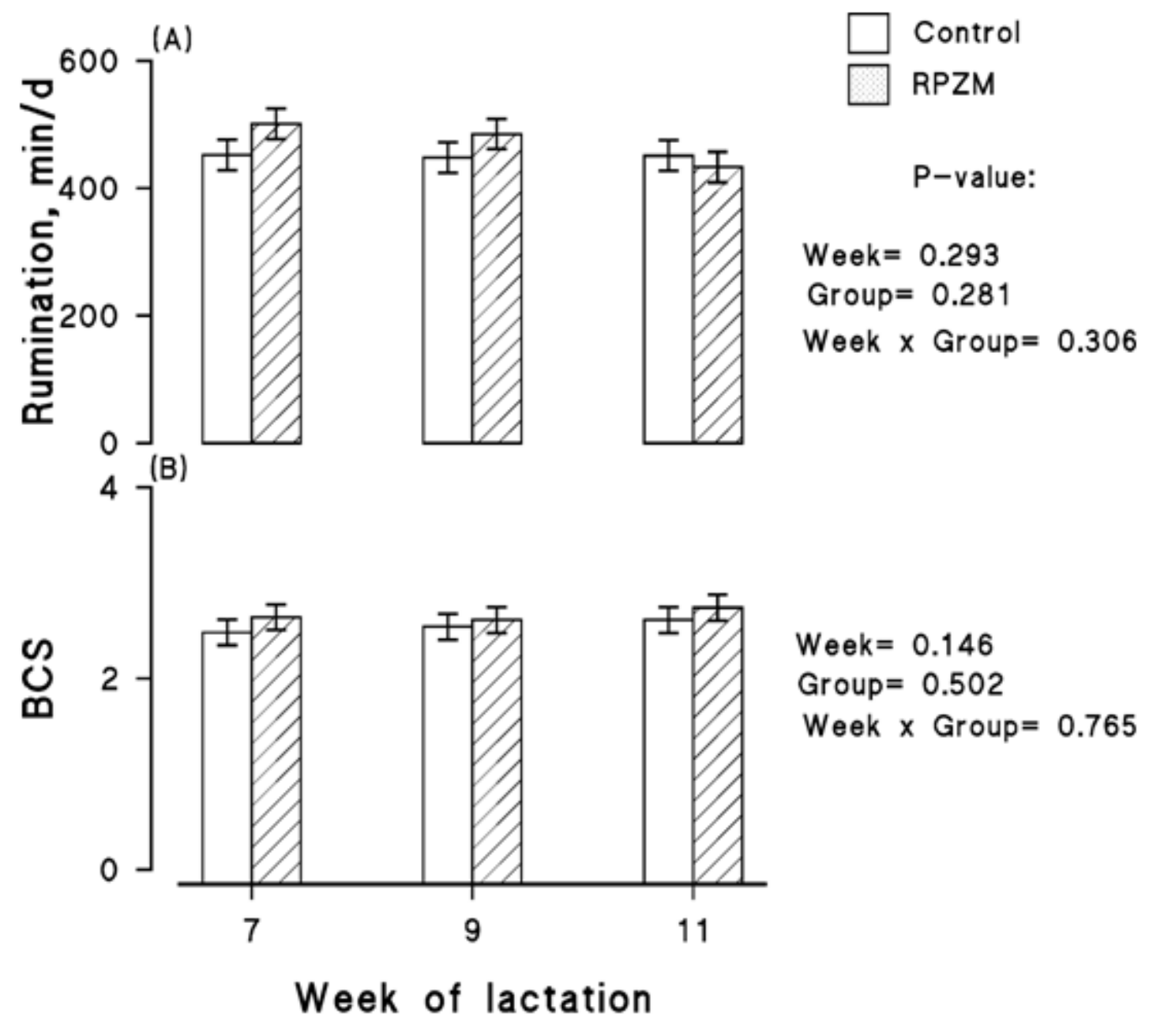

Figure 3

Rumination activity and body condition score Rumination time (panel A) and body condition score (BCS; panel B) of high producing Holstein cows supplemented without (Control) or with rumen-protected ZincMethionine complex (RPZM) during a long-term environmental heat stress.Values are Means \pm standard error of means. 


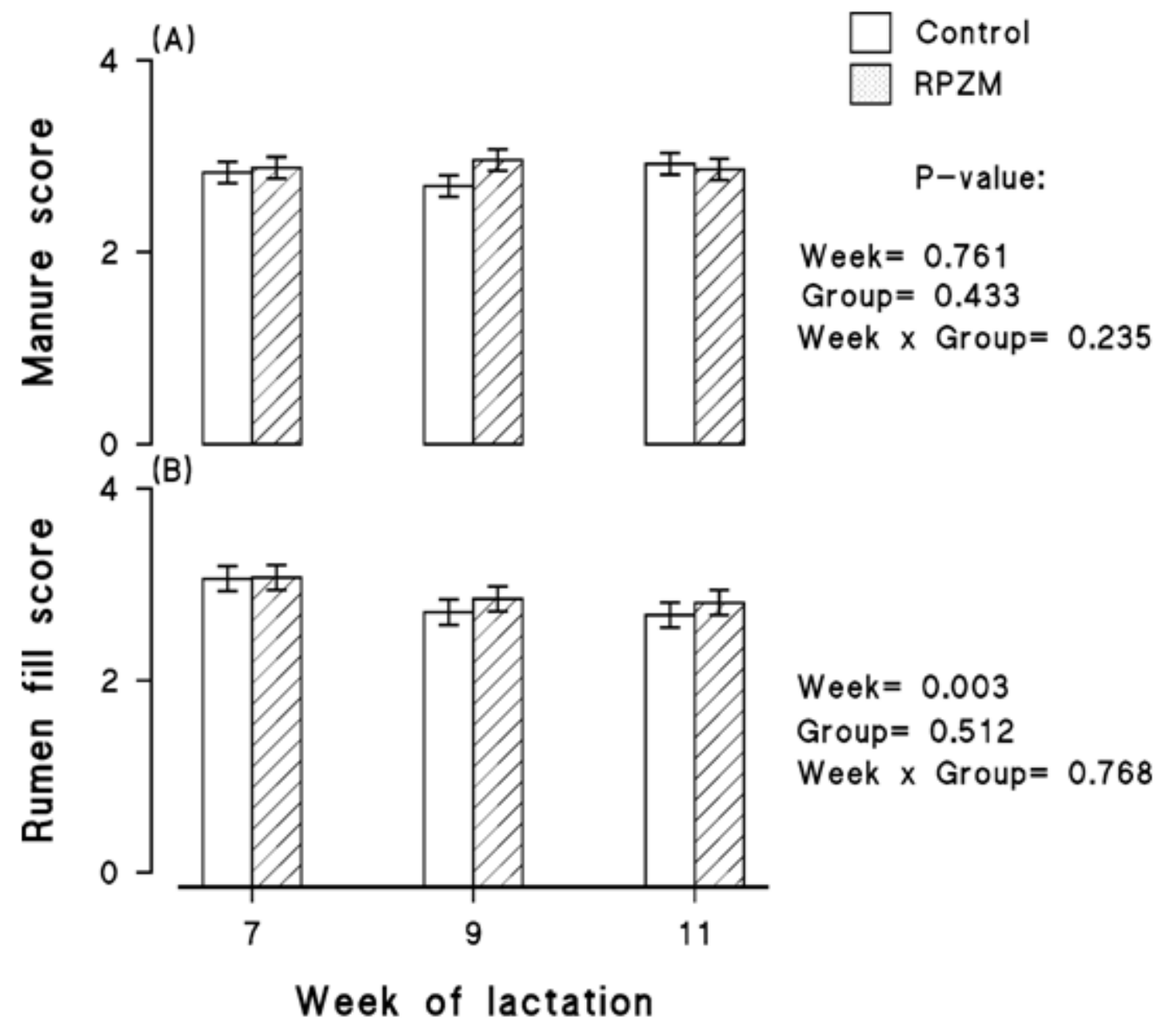

Figure 4

Manure and rumen fill score Manure Score (panel A) and Rumen fill score (panel B) of high producing Holstein cows supplemented without (Control) or with rumen-protected Zinc-Methionine complex (RPZM) during a long-term environmental heat stress.Values are Means \pm standard error of means. 


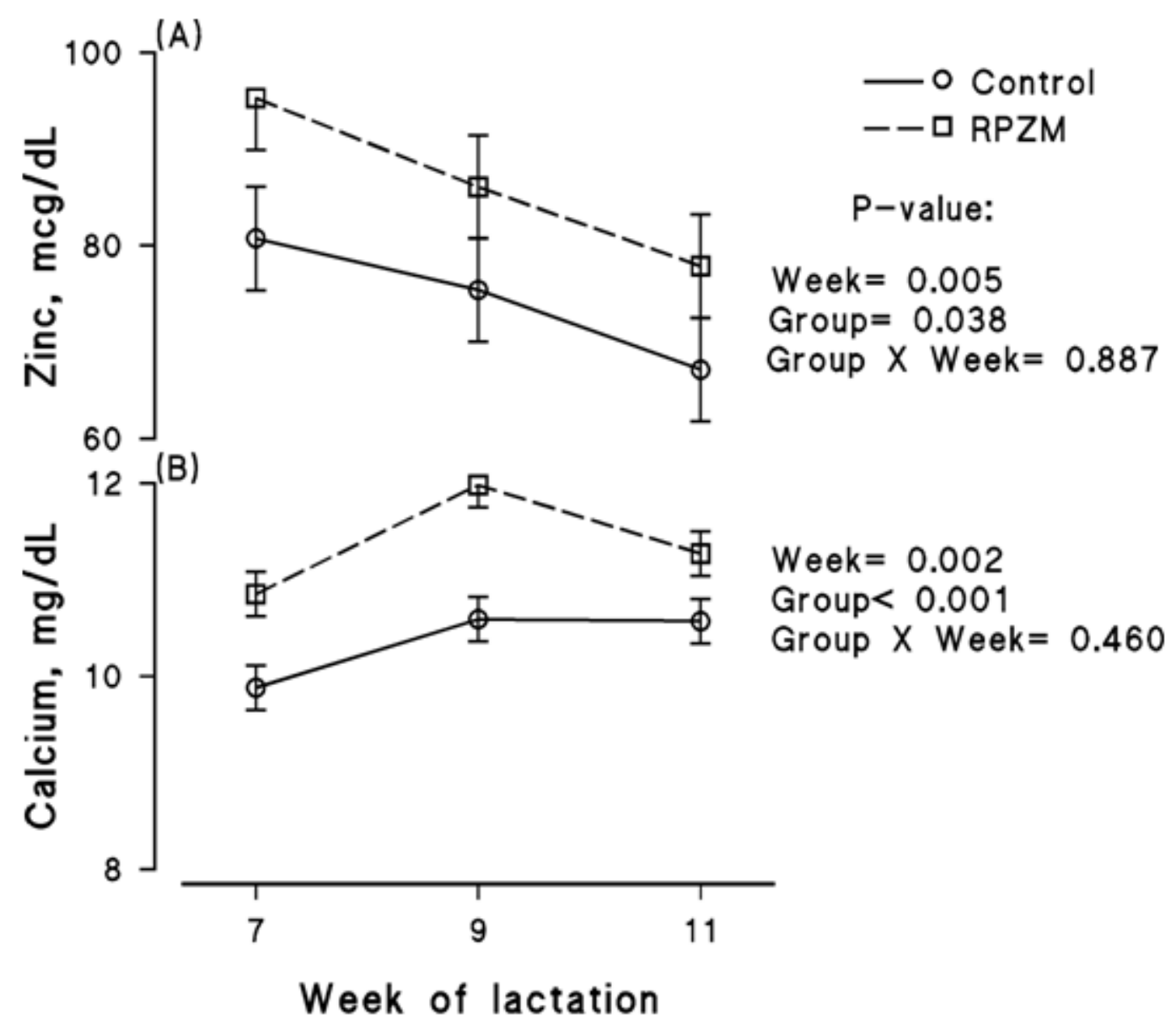

Figure 5

Circulating concentration of zinc and calciumBlood serum concentration of zinc (panel $A$ ) and calcium (panel B) of high producing Holstein cows, trough lactation weeks 6 to 11, supplemented without (Control) or with rumen-protected Zinc-Methionine complex (RPZM) during a long-term environmental heat stress.Values are Means \pm standard error of means. 


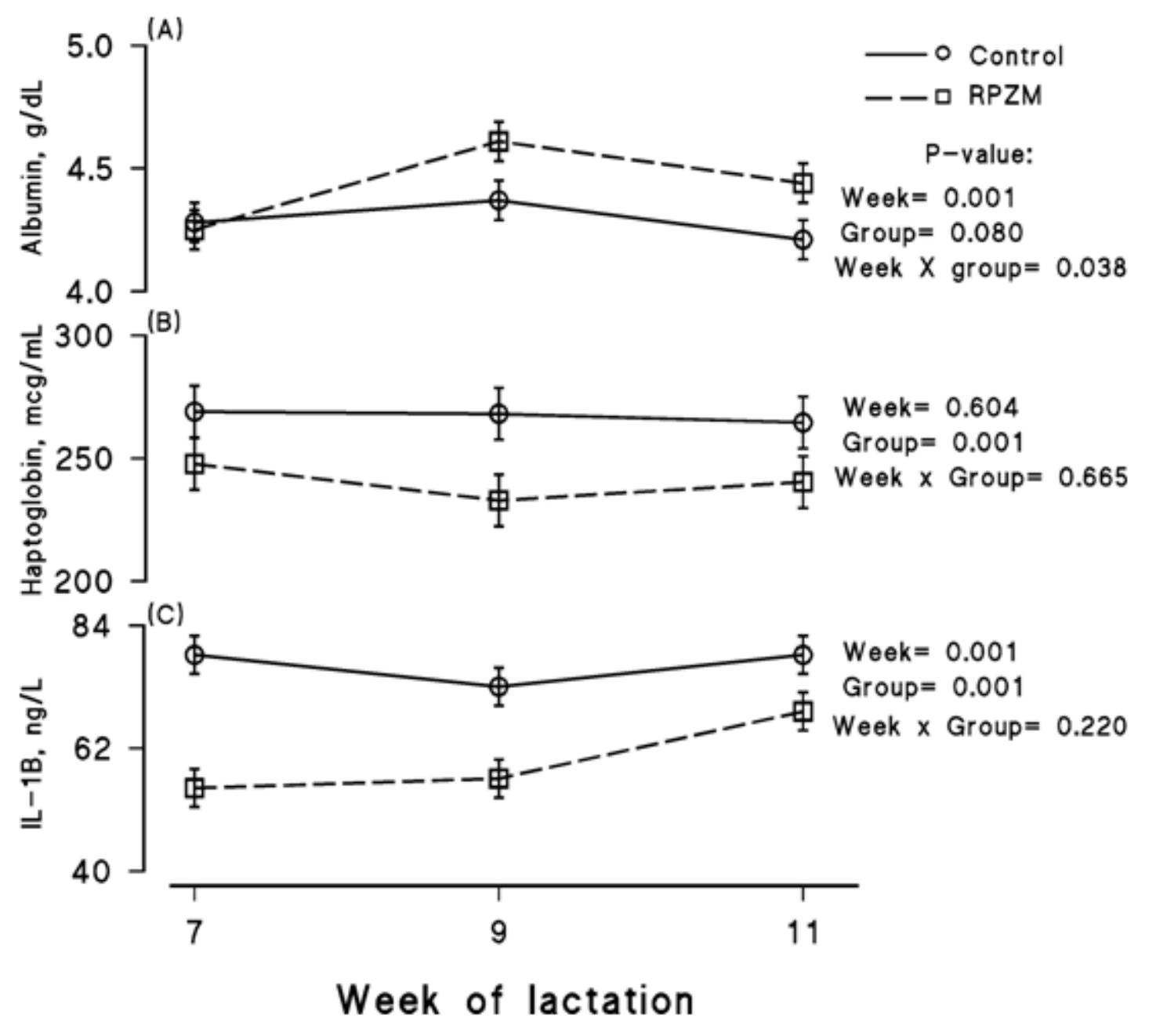

Figure 6

Circulating concentration of albumin, haptoglobin and Interleukin-1 betaBlood serum concentration of albumin (panel A), haptoglobin (panel B) and Interleukin-1 beta (IL-1B; panel C) of high producing Holstein cows, trough lactation weeks 6 to 11, supplemented without (Control) or with rumen-protected Zinc-Methionine complex (RPZM) during a long-term environmental heat stress.Values are Means \pm standard error of means. 


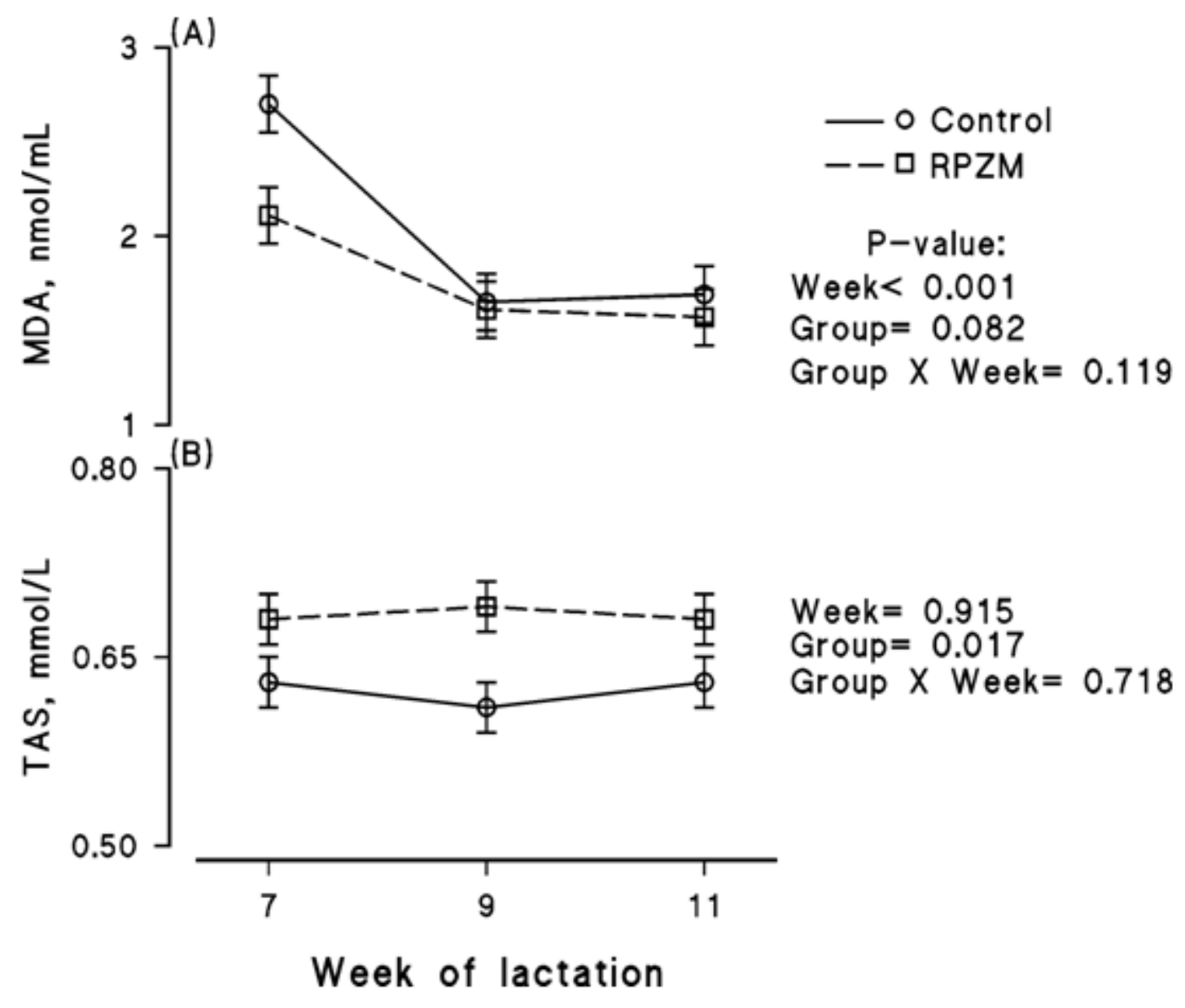

Figure 7

Circulating concentration of malondialdehyde and total antioxidant statusBlood serum concentration of malondialdehyde (MDA; panel A) and total antioxidant status (TAS; panel B) of high producing Holstein cows, trough lactation weeks 6 to 11, supplemented without (Control) or withrumen-protected ZincMethionine complex (RPZM) during a long-term environmental heat stress. Values are Means \pm standard error of means.

\section{Supplementary Files}

This is a list of supplementary files associated with this preprint. Click to download.

- SupplemantaryfileDaneshMesgaranetal.docx 